\title{
Modelo de atención integral de salud bucal en Pachacútec, Callao
}

\author{
Integral model of oral health care in Pachacútec, Callao
}

\section{Resumen}

El objetivo general del modelo fue elevar la calidad de atención odontológica incrementando la población sana y disminuyendo la morbilidad de enfermedades bucodentales a través de acciones integrales de promoción, prevención y acciones asistenciales de primer nivel de atención en los individuos, familias y comunidad. El tipo de estudio es descriptivo transversal. Se revisó el Análisis de Situación de Salud (ASIS) de la Microred 03, se aplicó la ficha OMS y se realizaron exámenes bucales a 100 familias y 75 niños de la Institución Educativa N.$^{\circ}$ 5130. Las primeras causas de mortalidad es la hipertensión arterial; la segunda es la diabetes mellitus, y en tercer lugar la neumonía. Las tres primeras causas de morbilidad son infecciones agudas de las vías respiratorias, enfermedades infecciosas intestinales y enfermedades de la cavidad bucal, siendo la caries la enfermedad que afecta al $80 \%$ (76\% a la edad de seis ańos, $80 \%$ a la edad de 12 ańos y $84 \%$ en el grupo de los 15 ańos de edad). La enfermedad periodontal afecta al $20 \%$, las maloclusiones $57,34 \%$. El $56 \%$ de los estudiantes tiene higiene bucal regular, $19 \%$ tiene higiene bucal mala y el 18,7 \% tiene higiene bucal buena. Se concluyó que la población estudiantil presenta alta prevalencia de caries dental (80\%), alto índice CPO (5.56 a los seis años) y maloclusiones. Existe un gran porcentaje de nińos con higiene bucal regular y mala.

Palabras clave: epidemiología, salud bucal, índice de caries dental, higiene oral, diagnóstico bucal, odontología preventiva.

\section{Abstract}

The principal aim of the model was to raise the quality of dental care through comprehensive measures for promotion, prevention and healing in the community. Specific aims were to increase the healthy population through promotion of health and reduce the morbidity of oral diseases by preventive actions and first class welfare care. A cross-sectional descriptive study. Revised Health Situation Analysis (HSA) of the Microgrid 03, the modified tab WHO oral health assessment is applied and oral exams to 100 families and 75 children of School N. ${ }^{\circ} 5130$. The leading causes of death were hypertension, diabetes mellitus and pneumonia. The leading causes of morbidity were acute respiratory infections, intestinal infectious diseases and diseases of the oral cavity. Tooth decay affects $80 \%$ group of 6 to 15 years, followed by $57.34 \%$ of malocclusion and periodontal disease with $20 \%$. Regarding oral hygiene most children have regular status (56\%), followed by poor hygiene $(25.3 \%$ ) and only $18.7 \%$ with good oral hygiene. We conclude that the student population shows high prevalence of dental caries, malocclusion and few maintain good oral hygiene, which reveals the need for integral treatment by the proposed model and the agreement between the San Marcos Faculty of Dentistry and Educational Institutions of EUS Ventanilla, Callao.

Key words: epidemiology, dental health survey, DMF index, oral hygiene index, oral diagnoses, preventive dentistry

\section{Introducción}

En nuestro país debido a sus características geográficas, económicas, sociales y culturales se presentan poblaciones aisladas y de gran vulnerabilidad, que no tienen acceso adecuado a los servicios de salud, especialmente a la atención odontológica. La salud buco dental cada vez se deteriora más y la prestación de atención odontológica es cada vez más escasa lo que hace necesario la implantación de programas de atención que cubran los aspectos preventivos y curativos.

La salud bucal en el país representa en la actualidad uno de los mayores problemas de salud pública, debido a que este componente registra una elevada prevalencia de patologías odontoestomatológicas en la población entre 90-95\% y afecta a todas las etapas de vida, particularmente a los niños, requiriendo estrategias para atender estas patologías.

Entre las patologías bucales, la caries dental es señalada como la más prevalente en un $95 \%$, estimando que a los 12 años de edad, un niño presenta en promedio 6 piezas comprometidas por caries dental, siendo las primeras molares permanentes las que frecuentemente están afectadas y dentro de estas, las molares inferiores presentan mayor incidencia. Siguen las enfermedades periodontales $85 \%$, maloclusiones $80 \%$, enfermedades congénitas (labio-maxilo-palatino) y cáncer oral. La prevención primaria para reducir el riesgo de caries desde una perspectiva nutricional, se basa en el mantenimiento de una dieta equilibrada al establecer guías dietéticas. ${ }^{1}$

\section{Artículo Original}

\section{Marco Tulio Madrid \\ Chumacero ${ }^{1}$, Antonia \\ Castro Rodriguez ${ }^{1}$, Juana \\ Echeandía Arellano², Sylvia \\ Chein Villacampa ${ }^{1}$, Jorge \\ Villavicencio Gastelú ${ }^{3}$, Adelmo Cuentas Robles ${ }^{3}$, Ricardo Vásquez Olivares ${ }^{1}$}

\footnotetext{
${ }^{1}$ Dpto. Académico Estomatología Preventiva y Social. Facultad de Odontología. Universidad Nacional Mayor de San Marcos.

${ }^{2}$ Facultad de Medicina. Universidad Nacional Mayor de San Marcos.

3 Dpto. Académico Médico Quirúrgico. Facultad de Odontología. Universidad Nacional Mayor de San Marcos.
}

Correspondencia:

Mg. Marco Tulio Madrid Chumacero Jr. Restauración 373. Dpto. 102, Lima 5 Teléf.: 332-3865

E-mail: marcomdrd24@hotmail.com

Fecha de recepción: 20-08-10

Fecha de aceptación: 18-04-11

A escala mundial, las tasas de prevalencia y los patrones de presentación de las enfermedades orales han cambiado considerablemente ${ }^{2,3}$, presentándose en la mayoría de países desarrollados una reducción significativa tanto en la prevalencia como en la experiencia de caries dental en niños y adolescentes durante las dos últimas décadas. En contraste, en países en vías de desarrollo aún se observan altos niveles de caries den$\mathrm{tal},{ }^{4}$ especialmente en países donde las intervenciones comunitarias de tipo promocional o preventivo no han sido firmemente establecidas. En el Perú, el $84,0 \%$ de los niños presentan caries dental a los 12 años de edad, con un promedio de 3,1 dientes permanentes con experiencia de caries dental. ${ }^{4,5} \mathrm{Se}$ reconoce además que el componente cariado explica la mayor parte de la 
experiencia de caries dental. De hecho, algunos estudios han demostrado que niños de comunidades de escasos recursos tienen un nivel significativamente mayor de caries dental que niños provenientes de familias con ingresos promedio. La Organización Mundial de la Salud (OMS) ha definido la caries dental como un proceso localizado de origen multifactorial que se inicia después de la erupción dentaria, determinando el reblandecimiento del tejido duro del diente y evoluciona hasta la formación de una cavidad. Si no se atiende oportunamente, afecta la salud general y la calidad de vida de los individuos de todas las edades. ${ }^{6}$

La caries dental junto con la enfermedad periodontal, constituyen el mayor porcentaje de morbilidad dentaria durante toda la vida de un individuo. Afecta a personas de cualquier edad, sexo y raza; teniendo una mayor presencia en sujetos de bajo nivel socioeconómico. Esta situación guarda relación directa con un deficiente nivel educativo, una mayor frecuencia en el consumo de alimentos ricos en sacarosa entre las comidas y ausencia de hábitos higiénicos. ${ }^{7}$ Afecta primordialmente a la primera edad mientras que las periodontopatías se manifiestan principalmente en los adultos. $^{8}$

A pesar de existir metodos preventivos capaces de dominarlas, controlarlas y/o erradicarlas, la odontología en Latinoamérica continúa usando tecnología curativa, costosa, compleja e ineficiente, y se sigue ofreciendo al $90 \%$ de la población la exodoncia como única solución. ${ }^{6}$

Constituye una importante fuente de dolor para el ser humano y es origen de grandes pérdidas económicas para la sociedad, unido a los elevados costos de los servicios odontológicos se han convertido en un bien de consumo cada vez más inaccesible a un gran sector de la población.?

\section{Material y método}

Se realizó un estudio epidemiológico transversal descriptivo en la población de escolares de la Institución Educativa N. 5130 (población de 75 niños) con edades índice de 6 años, 12 años y 15 ańos, utilizando formularios OMS de Evaluación de la salud buco-dental 1997 (Modificado).

También se hicieron las siguientes atenciones educativo-preventivas: a) Charla educativa (motivación) a padres de fa- milia, escolares, profesores; b) Revelado de placa bacteriana por medio de sustancia colorante (violeta de genciana); c) Índice de Placa Bacteriana simplificado; d) Eliminación de Placa Bacteriana, por medio del cepillado; y e) Uso del hilo dental como complemento del cepillado y Profilaxis con Flúor aplicando bańos de Flúor Gel (4 aplicaciones al año).

Se realizó paralelamente al estudio en escolares de la IE 5130 un estudio epidemiológico transversal descriptivo a los miembros de 100 familias en la zona $\mathrm{F}$ que es la zona cercana al colegio y cercana al Centro comunal utilizando formularios OMS de Evaluación de la salud buco-dental 1997 (Modificado).

Las actividades a realizar en el proyecto de 5 años corresponden a dos fases. La primera fase, en el año 2008, consistió en actividades de promoción de salud bucodental y prevención de enfermedades de la boca y el estudio epidemiológico para caracterizar el estado de salud bucal de la población estudiantil. En el año 2009 consistió en actividades de intervención con la técnica atraumática con ionómeros de vidrio (ATR). La segunda fase del proyecto comprende atención recuperativa, con equipos dentales móviles en las Instituciones Educativas (IE) la cual tiene como objetivo aplicar modelo de atención integral a la población estudiantil de Pachacútec, Ventanilla, Callao, lo que conlleva al establecimiento de un Módulo de atención básica Integral en Atención Primaria de salud bucal en convenio con la Facultad de Odontología, UGEL, y otras instituciones. Esta fase tendrá una duración de 3 años. En el año 2010 se ha desarrollado un modelo de Atención Integral de Salud Bucal para escolares en la IE 5129 que servirá de estudio

Tabla 1. Prevalencia de caries dental en niños a las edades de 6, 12 y 15 años. IE 5130. Pachacútec, Ventanilla, Callao, 2008

\begin{tabular}{lccc}
\hline Edad & Niños examinados & Niños afectados por caries & Porcentaje (\%) \\
\hline 6 ańos & 25 & 19 & 76 \\
12 ańos & 25 & 20 & 80 \\
15 ańos & 25 & 21 & 84 \\
Total & 75 & 60 & 80 \\
\hline
\end{tabular}

Tabla 2. Índice CPOD en 100 familias, Pachacútec, Ventanilla, Callao, 2008

\begin{tabular}{lcccc}
\hline & Suma & Promedio & $\begin{array}{c}\text { Desviación } \\
\text { Estándar }\end{array}$ & $\begin{array}{c}\text { Intervalo Con- } \\
\text { fianza 95\% }\end{array}$ \\
\hline Pieza permanente cariada & 2319 & 4,42 & 4,434 & $4,04-4,80$ \\
Pieza permanente perdida & 1111 & 2,12 & 3,764 & $1,80-2,44$ \\
Pieza permanente obturada & 917 & 1,75 & 4,412 & $1,37-2,13$ \\
Total & 4347 & & & \\
\hline
\end{tabular}

piloto para luego aplicar esta propuesta para todas las Instituciones Educativas de Pachacútec, Ventanilla, Callao, que será propuesta para los ańos 2012 y 2013.

\section{Resultados}

Al revisar el Análisis de la Situación de salud (ASIS) los resultados revelan que Pachacútec tiene una población total de 59452 habitantes, de los cuales 30104 pertenecen al sexo masculino y 29348 al sexo femenino con una pirámide poblacional caracterizada por su ancha base lo cual indica un porcentaje amplio para los menores de 15 ańos, aunque presenta también una población considerable de la tercera edad. Presenta una tasa de mortalidad infantil de 3,5 x 1000 nacidos vivos, la cual ha ido disminuyendo desde 1999. Tasa bruta de mortalidad a 2003 de $1.2 \times 1000$ habitantes. Como primera causa de mortalidad se destaca la hipertensión arterial que afecta mayormente a los grupos de edad de 20-49 y 50-64 y al grupo de 65 y en segundo lugar aparece la diabetes mellitus afectando a los mismos grupos de edad que la hipertensión, en tercer lugar la neumonía, la cual afecta a casi todos los grupos de edad, en cuarto lugar la tuberculosis pulmonar y en quinto lugar la enfermedad cerebro vascular. Las tres primeras causas de morbilidad son infecciones agudas de las vías respiratorias, enfermedades infecciosas intestinales y enfermedades de la cavidad bucal.

Los resultados de salud bucal corresponden a la aplicación de la ficha de la OMS a la población escolar, y correspondió a la información de niños de edades índice 6 años, 12 años y 15 años siendo un total de 75 niños examina- 
Tabla 3. Índice CPOD en escolares del IE N. ${ }^{\circ}$ 5130, Pachacútec, Callao, 2008

\begin{tabular}{lcccc}
\hline & Cariado & Perdido & Obturado & CPO \\
\hline Total & 196 & 4 & 14 & 2,61 \\
6 años & 100 & 9 & 0 & 5,56 \\
12 años & 53 & 2 & 0 & 2,20 \\
15 años & 47 & 3 & 14 & 2,56 \\
\hline
\end{tabular}

dos. La caries dental afecta gran porcentaje de los nińos examinados. (Tabla 1).

Al examinar a los miembros de la familia encontramos que predominan las piezas cariadas, seguidas por las perdidas y obturadas que se ubican en un nivel similar. El índice CPOD fue de 8,29 $(4.42+2,12+1.75)$ (Tabla 2).

Al examinar a los niños escolares encontramos 396 piezas dentales con caries y un índice CPOD de 2,61, siendo los niños de 6 años los más afectados con un índice de 5,56 (Tabla 3).

La enfermedad periodontal afecta al $18.7 \%(14 / 75)$ del total de los 75 nińos examinados, existiendo $83,4 \%$ de sextantes libres de enfermedad periodontal y $16,6 \%$ de sextantes afectados. El porcentaje de sextantes afectados: $16,60 \%$. (75/450) La mayor cantidad de sextantes afectados correspondió a la edad de 15 años (Tabla 4).

Tabla 4. Sextantes sanos y afectados por enfermedad periodontal en escolares de la IE N. ${ }^{\circ}$ 5130, Pachacútec, Ventanilla, 2008.

\begin{tabular}{lcc}
\hline Edad & Sextantes sanos & Sextantes con sangrado gingival \\
\hline 6 ańos & 140 & 10 \\
12 ańos & 123 & 27 \\
15 ańos & 112 & 38 \\
Total & 375 & 75 \\
\hline
\end{tabular}

Tabla 5. Maloclusiones en escolares de la IE N. ${ }^{\circ}$ 5130. Pachacútec. Ventanilla 2008

\begin{tabular}{ccccc}
\hline Código Maloclusiones & \multicolumn{3}{c}{ EDADES ÍNDICE } & Total \\
\hline 0 & 6 años & 12 años & 15 años & \\
1 & 11 & 5 & 16 & 32 \\
2 & 13 & 15 & 7 & 35 \\
Total afectados & $\mathrm{v}$ & 5 & 2 & 8 \\
& 14 & 20 & 9 & 43 \\
\hline
\end{tabular}

Tabla 6. Estado de higiene oral en escolares de la IE N. ${ }^{\circ}$ 5130, Pachacútec, Ventanilla, Callao, 2008

\begin{tabular}{lcccccc}
\hline Edad & \multicolumn{2}{c}{ Buena higiene } & \multicolumn{3}{c}{ Regular higiene } & \multicolumn{2}{c}{ Mala higiene } \\
& $\mathrm{n}$ & $\%$ & $\mathrm{n}$ & $\%$ & $\mathrm{n}$ & $\%$ \\
\hline 6 ańos & 1 & 5,6 & 13 & 72,2 & 4 & 22,2 \\
12 años & 8 & 22,2 & 20 & 55,6 & 8 & 22,2 \\
15 años & 5 & 23,8 & 9 & 2,9 & 7 & 33,3 \\
Total & 14 & 18,7 & 42 & 56,0 & 19 & 25,3 \\
\hline
\end{tabular}

digo 1 la que más se presenta. El 56,0 $\%$ de los estudiantes tiene higiene bucal regular, 25,3\% tiene higiene bucal mala, y el $18,7 \%$ tiene higiene bucal buena (Tabla 6 ).

\section{Discusión}

Estudios de prevalencia de caries realizados en Espańa, los países nórdicos, Bélgica, República de Irlanda, Suiza, Australia (Spencer \& col. 1994); África y República de China (Fejerskov, 1994) demuestran un descenso en la frecuencia y severidad de la enfermedad. ${ }^{9,10,11,12,13,14,15}$ A su vez Konig en 1994 refiere como uno de los aspectos discutidos en la Segunda Conferencia Internacional sobre Cambios en la Prevalencia de caries, la bimodalidad de la distribución de la enfermedad en los distintos grupos poblacionales, provocada por las diferencias socioeconómicas. ${ }^{16}$

En el caso del Perú se siguen manteniendo índices CPOD altos como es el caso de la población estudiantil de la IE N. ${ }^{\circ} 5130$ con índices CPOD mayores de 5 . Estos resultados relacionan la caries dental y poblaciones de extrema pobreza. La principal meta de salud buco dental para el año 2000 propuesto por la OMS en el año 1979, establece no más de 3 dientes CPOD a los 12 años de edad. ${ }^{17}$ Estas metas mundiales establecidas por la OMS y FDI contribuyen a que los esfuerzos de los países se concentren en la prevención de enfermedades buco-dentales.

Los resultados contrastan con los encontrados en nińos venezolanos, se observó que el promedio de CPOD en niños de 6 a 12 ańos de la Escuela Básica "Cruz Millán García" del Municipio Antolín del Campo, Estado Nueva Esparta, se incrementa a medida que aumenta la edad. Destacándose las edades críticas entre los 11 y 12 años con un índice CPOD de 1,75 y 2,75 , respectivamente. El promedio de dientes obturados respectivamente no aumenta en la misma proporción que los dientes cariados. ${ }^{7}$

Así mismo se observan diferencias con el estudio realizado en niños de Nicaragua, donde se encontró una prevalencia de caries en la dentición temporal a los 6 ańos de edad fue del $72,6 \%$ y la de la dentición permanente a los 12 años fue del 45,0 \%. La media de los índices de caries (ceod y CPOD) para la muestra fue $2,98 \pm 2,93$ (n 1125$)$ y $0,65 \pm 1,43$ (n 1379 ). ${ }^{8}$ 


\section{Conclusiones}

La alta prevalencia de caries dental $(80 \%)$ con un alto índice CPOD (5.56 a los seis años) y maloclusiones $(57,34 \%)$ en la población estudiantil de la Institución Educativa N.o 5130 de Pachacútec, Ventanilla es un problema de salud en estos nińos.

Es necesario intervenir con un enfoque de determinantes sociales de salud bucal y factores de riesgo por cada enfermedad bucal mediante un modelo de atención integral como el propuesto convenio entre la Facultad de Odontología UNMSM y las Instituciones Educativas de la Unidad de Servicios Educativos (USE) correspondiente a Ventanilla, Callao.

\section{Referencias bibliográficas}

1. Barroso JB, Guinot FJ, Barbero VC, Bellet LD. La importancia de la dieta en la prevención de la caries. Gaceta Digital Dental. Año 2007. Consulta 25 Mayo 2011. Disponible en: http://www.gacetadental. com/noticia/2630/

2. Nithila A, Bourgeois D, Barmes DE, Murtomaa H. WHO Global Oral Data Bank, 1986-96: an overview of oral health surveys at 12 years of age. Bull World Health Organ 998; 76(3):237-44.

3. Pakhomov GN. Future trends in oral health and disease. Int Dent J 1999; 49(1):27-32
OPS. La salud en las Américas. Edición 2002. Washington DC: Organización Panamericana de la Salud; 2002.

4. Beltran-Aguilar ED, Estupinan-Day S, Baez R. Analysis of prevalence and trends of dental caries in the Americas between the 1970s and 1990s. Int Dent J 1999; 49(6):322-9

5. PAHO. Promoting Oral Health: The use of salt fluoridation to prevent dental caries. Washington DC: Pan American Health Organization; 2005.

6. Irigoyen M.; Zepeda A.; Sánchez L. Prevalencia e Incidencia de Caries Dental y Hábitos de Higiene Bucal en un Grupo de escolares del Sur de la Ciudad de México. Investigación Revista ADM2001:53 (3):98-104

7. Mendes D, Caricote N. Prevalencia de Caries Dental en Escolares de 6 a 12 años de edad del Municipio Antolín del Campo, Estado Nueva Esparta, Venezuela. (2002-2003). Revista Latinoamericana de Ortodoncia y dontopediatria "Ortodoncia. $w s$ ” edición electrónica Diciembre 2003. www.ortodoncia.ws

8. Herrera MS, Medina-Solis C E, Maupomé G. Prevalencia de caries dental en escolares de 6-12 años de edad de León, Nicaragua. Gac Sani t. 2005; 19(4):302-6

9. Majen L, Garía R, Josep R, Manau C, Cuenca E, Krasse B. Dietary habits and dental caries in population of spanish scoolchildren with low levels of caries experiencie. Caries Res.1993; 27(6):4 88-494. DOI:10.1159/000261586

10. Norway F. Caries prevalence in the Nordic countries Int Dent J. 1994; 44 (4):371-385.

11. Truin GJ, König KG, Bronkhorst EM. Caries prevalence in Belgium and the Netherlands. Int. Dent $J$ 1994; 44 (4 Suppl 1):379-385.

12. O'Mullane D, Whelton H. Caries prevalence in the Republic of Irland. Int Dent J. 1994; 44 (4 Suppl 1): 387-391.

13. Marthaler T. Steiner M., Menghini G y Band A. 1994 Caries prevalence in Switzerland. Int Dent J. 1994; 44 (4 Suppl 1): 393-401.

14. Spencer A. Davies M. Slade Gary and Brennan D. 1994 Caries prevalence in Australia. Int Dent J. 1994; 44 (4 Suppl 1): 415-48.

15. Fejerskov O. Baelum V., Livan W Y Manji F. 1994 Caries prevalence in africa in the people's republic of China. Int Dent J. 1994; 44 (4 Suppl 1): 425-433.

16. Konig K.G. Implications of changes in caries prevalence on research. Int Dent J. 1994; 44 (4 Suppl 1): 451-456.

17. OMS/FDI. Metas de salud bucal para el año 2000. Ginebra: OMS/ FDI; 1979. 